\title{
Effects of Phosphorus and Iron on Microstructures and Mechanical Properties in NiCrFe-Based Alloys
}

\author{
Xin-Tong Lian ${ }^{1,2} \cdot$ Wen-Ru Sun ${ }^{1} \cdot{\text { Fang } \operatorname{Liu}^{1} \cdot \text { Dan-Dan Zheng }}^{1} \cdot$ Xin Xin $^{1}$
}

Received: 21 March 2018/Revised: 23 April 2018/Published online: 17 August 2018

(C) The Chinese Society for Metals and Springer-Verlag GmbH Germany, part of Springer Nature 2018

\begin{abstract}
The microstructures and mechanical properties, especially creep properties, of the NiCrFe-based alloys with various contents of phosphorus and iron were investigated. The results showed that the tensile yield strength decreased with increasing iron contents while had no obvious change with the addition of phosphorus. For creep properties, the alloy with $15.8 \mathrm{wt} \%$ iron and $0.09 \mathrm{wt} \%$ phosphorus possessed the longest creep life $(679 \mathrm{~h})$ among all alloys. Only $M_{23} \mathrm{C}_{6}$ was formed in the alloys with low phosphorus contents, while both intergranular $M_{3} \mathrm{P}$ and $M_{23} \mathrm{C}_{6}$ precipitated with the increment of phosphorus, which enhanced the strength of grain boundary by hindering the movements of dislocations during creep tests. The reasons for the enhancement of creep life were mainly related to the solid solution strengthening effect of phosphorus and optimization of grain boundary precipitations by phosphorus.
\end{abstract}

Keywords NiCrFe-based alloys $\cdot$ Phosphorus $\cdot$ Iron $\cdot$ Microstructures $\cdot$ Creep properties

\section{Introduction}

Nowadays, many researches have been focused on the use of phosphorus as an alloying element in Ni-based superalloys $[1,2]$. Phosphorus was regarded as a deleterious impurity and consequently restricted to low levels $(<0.015 \mathrm{wt} \%)$ to minimize its harmful effects [3]. In recent years, it draws attention that moderate phosphorus benefits the mechanical properties of some superalloys markedly. Therefore, one of the methodologies to improve the stress and creep properties of Ni-based alloys is to add phosphorus into superalloys. Sun et al. found that the addition of phosphorus promoted the precipitation of $M_{23} \mathrm{C}_{6}$ and $M_{3} \mathrm{~B}_{2}$ and thus enhanced the stress-rupture life of GH761 [4-6]. It was also reported that phosphorus was dissolved in the $\gamma$ matrix of IN706 alloy and accelerated the precipitation of $\gamma^{\prime}$ phase [7], which indicated that the effect

Available online at http://link.springer.com/journal/40195

Wen-Ru Sun

wrsun@imr.ac.cn

1 Institute of Metal Research, Chinese Academy of Sciences, Shenyang 110016, China

2 School of Materials Science and Engineering, University of Science and Technology of China, Hefei 230026, China of phosphorus on intragranular precipitates was of great importance. For IN718 alloy, moderate addition of phosphorus improved the rupture life by several times without deteriorating other properties, such as strength and ductility [8-10]. Several mechanisms of how phosphorus works in superalloy were put forward to explain the beneficial effects, including interactions between phosphorus and dislocations, optimizing grain boundary precipitation and improving grain boundary oxidation resistance [11-13]. However, it is worthy noting that negative effects of phosphorus on stress-rupture life were also found in Waspaloy and IN783 in specified conditions. It is obvious that the special effects of phosphorus on mechanical properties depend on alloy systems strongly [14, 15]. The difference of composition in alloys such as the scale of Fe and Ni may occupy a dominant position. It is because that the solid solubility of matrix for phosphorus varies with the change in the Fe/Ni ratio. Furthermore, the effect of phosphorus on the interior grains should not be ignored because solid solution strengthening of phosphorus atoms may play an important role in improving the strength of the matrix. In addition, the real mechanism of phosphorus in matrix is still controversial and uncertain due to the complicated microstructures, although it has been studied for several years. 
In an effort to evaluate the selective effects of phosphorus in superalloys, various contents of iron and phosphorus have been added into experimental NiCrFe-based alloys. Strengthening elements such as $\mathrm{Al}, \mathrm{Ti}, \mathrm{Nb}$ were eliminated to remove the effects of gamma prime and double prime precipitates. In this paper, microstructures and mechanical properties of the $\mathrm{NiCrFe}$-based alloys were investigated to clarify the roles of iron and phosphorus in alloys. The mechanism for phosphorus effect on intergranular precipitates and the beneficial effects of phosphorus and iron on intragranular strength is elucidated.

\section{Experimental}

Four alloys with different phosphorus and iron additions were prepared by vacuum induction melting (VIM), and the meting and pouring were performed under the same conditions to avoid the influence of processing. Phosphorus was controlled at two levels of 0.025 and $0.09 \mathrm{wt} \%$ in two alloy systems, which are $\mathrm{Ni}-17 \mathrm{wt} \% \mathrm{Cr}-15 \mathrm{wt} \% \mathrm{Fe}$ and $\mathrm{Ni}-$ 17 wt $\% \mathrm{Cr}-30 \mathrm{wt} \% \mathrm{Fe}$, respectively. The chemical compositions are given in Table 1 . The ingots were forged into bars with a square section of $40 \mathrm{~mm} \times 40 \mathrm{~mm}$ and then hot-rolled into round bars with a diameter of $12 \mathrm{~mm}$ after soaked at $1080{ }^{\circ} \mathrm{C}$ for $2 \mathrm{~h}$. The as-rolled bars were annealed at $1100{ }^{\circ} \mathrm{C}$ for $20 \mathrm{~min}$ and followed by water quenching and then machined into standard tensile and creep samples. Tensile samples with a gauge length of $25 \mathrm{~mm}$ and a diameter of $5 \mathrm{~mm}$ were conducted to fracture at $650{ }^{\circ} \mathrm{C}$. The creep samples with the same size as tensile samples were crept to fracture at $650{ }^{\circ} \mathrm{C}$ with an initial stress of $150 \mathrm{MPa}$. The samples were crept under the same conditions and interrupted at a given time of $60 \mathrm{~h}$ within the steady creep stage. The hardness of alloys was measured by using the LECO microstructure tester LM247T system with the load of $50 \mathrm{~g}$ and holding time of $15 \mathrm{~s}$. Five points were measured for each sample, and the average value was calculated. Then, the microstructure of the crept samples was observed to elucidate the microstructural evolution during creep. The fracture surfaces of the tensile and creep samples were observed by using a scanning

Table 1 Chemical compositions of different NiCrFe-based alloys (mass fraction, \%)

\begin{tabular}{llllll}
\hline & $\mathrm{P}$ & $\mathrm{Cr}$ & $\mathrm{Fe}$ & $\mathrm{C}$ & $\mathrm{Ni}$ \\
\hline Alloy 1 & 0.025 & 17.17 & 15.2 & 0.039 & $\mathrm{Bal}$. \\
Alloy 2 & 0.09 & 17.42 & 15.8 & 0.041 & $\mathrm{Bal}$ \\
Alloy 3 & 0.025 & 17.11 & 30.5 & 0.044 & $\mathrm{Bal}$ \\
Alloy 4 & 0.09 & 17.32 & 30.1 & 0.040 & $\mathrm{Bal}$. \\
\hline
\end{tabular}

electron microscope (SEM). The samples for optical microscope (OM) and SEM observations were etched in a solution of $\left(5 \mathrm{~g} \mathrm{CuCl}_{2}+100 \mathrm{ml} \quad \mathrm{HCl}+100 \mathrm{ml}\right.$ $\mathrm{C}_{2} \mathrm{H}_{5} \mathrm{OH}$ ). The dislocations and precipitations in crept samples were characterized by using a transmission electron microscope (TEM) equipped with an energy-dispersive spectrometry (EDS).

\section{Results}

\subsection{Heat-Treated Microstructures}

The heat-treated microstructures of these four alloys before mechanical tests are shown in Fig. 1. All of the four alloys possess a fully recrystallized microstructure with an average grain size of $25 \mu \mathrm{m}$. Plenty of twins appear within the grains, while no precipitations can be observed in the grain interior or at the grain boundaries. No obvious difference is found in the microstructures of these NiCrFe-based alloys with various phosphorus and iron additions.

\subsection{Mechanical Properties}

The tensile properties at $650{ }^{\circ} \mathrm{C}$ of the alloys are listed in Table 2. The yield strength, ultimate strength and elongation of the $\mathrm{Ni}-17 \mathrm{wt} \% \mathrm{Cr}-15 \mathrm{wt} \% \mathrm{Fe}$ alloys are higher than those of $\mathrm{Ni}-17 \mathrm{wt} \% \mathrm{Cr}-30 \mathrm{wt} \% \mathrm{Fe}$ alloys with the same phosphorus content. It shows that the increasing iron addition from 15 to $30 \mathrm{wt} \%$ largely decreases the yield strength but slightly decreases the ultimate tensile strength and elongation. However, the addition of phosphorus scarcely influences the yield strength, ultimate strength and elongation of the alloys with the same iron content. It is found that the strength and elongation of alloy 1 and alloy 3 are slightly higher than those of alloy 2 and alloy 4, respectively. Therefore, the addition of iron deteriorates the tensile properties of the $\mathrm{NiCrFe}$-based alloys, while the addition of phosphorus has no obvious negative effects.

As shown in Fig. 2, the creep curves of the four tested alloys exhibit the typical three-stage characteristics, including primary stage with decreasing creep rate, the secondary or steady-state creep stage with a fixed creep rate and the tertiary creep stage with an accelerated creep rate. Phosphorus and iron additions hardly influence the duration of the primary stages of the NiCrFe-based alloys, which are less than $60 \mathrm{~h}$. However, the duration of the steady creep stages and tertiary creep stages is influenced by phosphorus and iron additions noticeably. The increase in phosphorus has no obvious influence on the duration of the steady-state creep stage of $\mathrm{Ni}-17$ wt $\% \mathrm{Cr}-30 \mathrm{wt} \% \mathrm{Fe}$ alloys, but greatly prolongs that of $\mathrm{Ni}-17 \mathrm{wt} \% \mathrm{Cr}-$ $15 \mathrm{wt} \% \mathrm{Fe}$ alloys. The durations of steady-state creep 

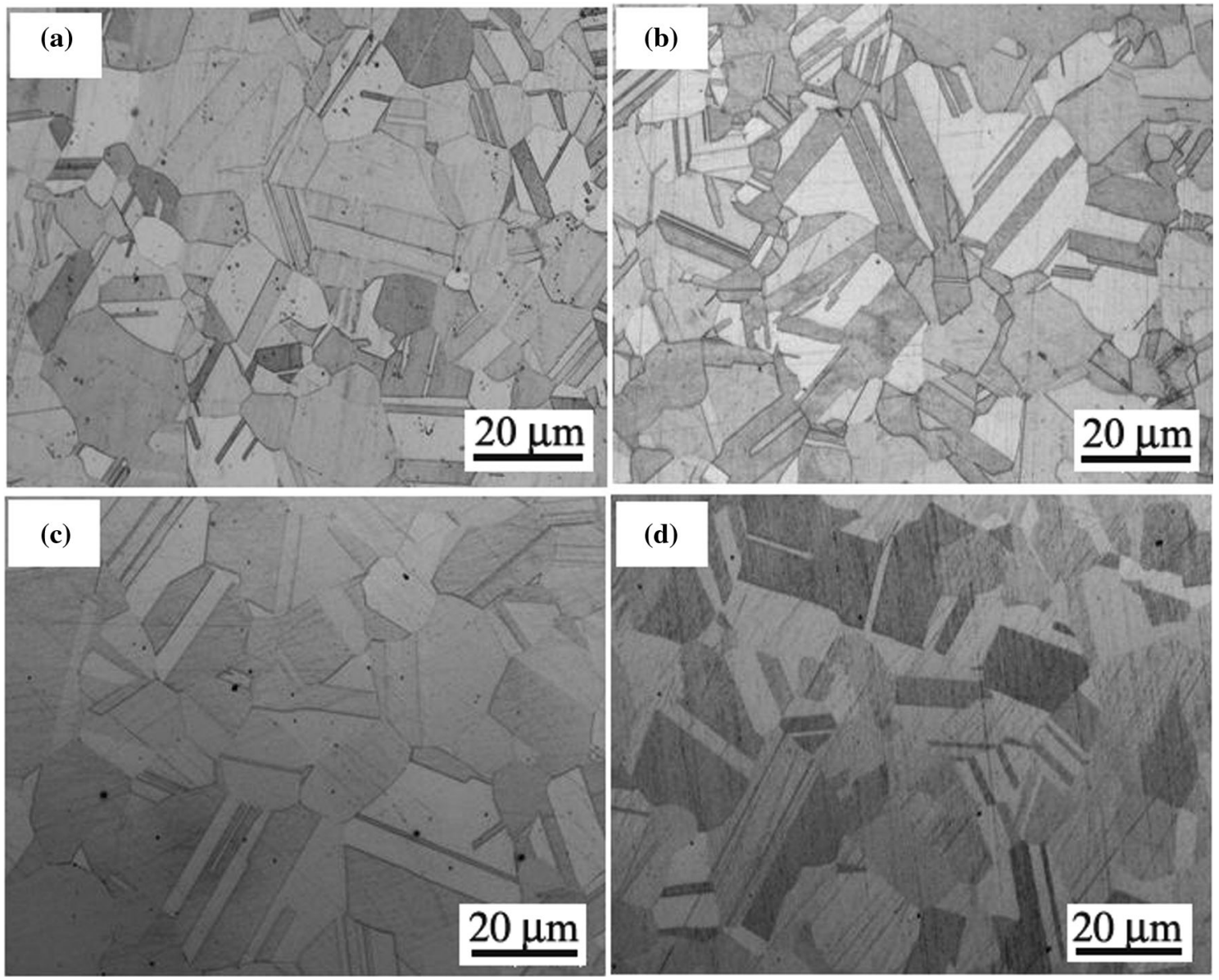

Fig. 1 As-heat-treated microstructure of NiCrFe-based alloys with different Fe and P additions: a alloy 1; b alloy 2; c alloy 3 ; d alloy 4

Table 2 Tensile properties of alloys at the temperature of $650{ }^{\circ} \mathrm{C}$

\begin{tabular}{lcccc}
\hline Alloy No. & Alloy 1 & Alloy 2 & Alloy 3 & Alloy 4 \\
\hline Yield strength (MPa) & 302 & 297 & 239 & 220 \\
Tensile strength (MPa) & 416 & 407 & 393 & 384 \\
Elongation (\%) & 64 & 61 & 56 & 55 \\
\hline
\end{tabular}

stages and the tertiary creep stages of $\mathrm{Fe}-17 \mathrm{wt} \% \mathrm{Cr}-$ $15 \mathrm{wt} \% \mathrm{Fe}$ alloys are longer than those of $\mathrm{Ni}-17 \mathrm{wt} \% \mathrm{Cr}-$ $30 \mathrm{wt} \% \mathrm{Fe}$ alloys, especially when the addition of phosphorus is added to the level of $0.09 \mathrm{wt} \%$. It can also be seen that the curves of $\mathrm{Fe}-17 \mathrm{wt} \% \mathrm{Cr}-15 \mathrm{wt} \% \mathrm{Fe}$ alloys always lie below those of $\mathrm{Fe}-17 \mathrm{wt} \% \mathrm{Cr}-30 \mathrm{wt} \% \mathrm{Fe}$ alloys, no matter the phosphorus addition stays at the level of $0.025 \mathrm{wt} \%$ or $0.09 \mathrm{wt} \%$. Moreover, the curves of the alloys with 0.09 wt $\%$ phosphorus always lie below those of alloys with $0.025 \mathrm{wt} \%$ phosphorus regardless of the variation of iron additions. It is apparent that decreasing iron additions or increasing phosphorus additions can reduce the creep rate, and the effect of phosphorus on creep property

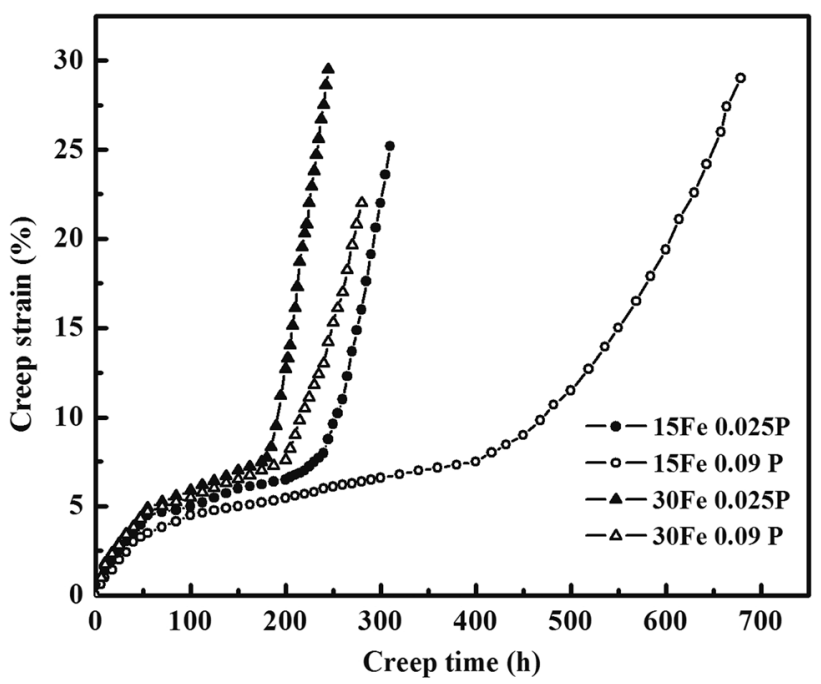

Fig. 2 Creep curves of NiCrFe-based alloys with different $\mathrm{P}$ and $\mathrm{Fe}$ additions

becomes much more noticeable when the iron content of alloys adds up to $15 \mathrm{wt} \%$. 
Table 3 Creep rupture life and elongation of $\mathrm{NiCrFe}$-based alloys at $650{ }^{\circ} \mathrm{C}$ with an initial stress of $150 \mathrm{MPa}$

\begin{tabular}{lcccc}
\hline Alloy No. & Alloy 1 & Alloy 2 & Alloy 3 & Alloy 4 \\
\hline Life (h) & 326 & 679 & 244 & 271 \\
Elongation (\%) & 25 & 30 & 30 & 23 \\
\hline
\end{tabular}

As shown in Table 3, the creep rupture lives of alloy 1 and alloy 2 are $326 \mathrm{~h}$ and $679 \mathrm{~h}$, respectively. It is apparent that the increase in phosphorus greatly increases the creep rupture life of the $\mathrm{Ni}-17 \mathrm{wt} \% \mathrm{Cr}-15 \mathrm{wt} \% \mathrm{Fe}$ alloy. However, the creep rupture lives of alloy 3 and alloy 4 are 244 and $271 \mathrm{~h}$, respectively. The addition of phosphorus slightly increases the creep rupture life of the $\mathrm{Ni}-$ $17 \mathrm{wt} \% \mathrm{Cr}-30 \mathrm{wt} \% \mathrm{Fe}$ alloy, which indicates that the beneficial effect of phosphorus on the creep rupture life is largely attenuated when the iron content increases from $15 \mathrm{wt} \%$ to $30 \mathrm{wt} \%$. It can also be seen from Table 3 that the increase in iron from $15 \mathrm{wt} \%$ to $30 \mathrm{wt} \%$ noticeably decreases the creep life, whatever level phosphorus stays at. The harmful effects of increasing iron contents on the lives of the $\mathrm{NiCrFe}$-based alloys are greatly amplified when the phosphorus addition increases to the level of $0.09 \mathrm{wt} \%$.

Figure 3 shows the change in micro-hardness of the inner grains in the $\mathrm{NiCrFe}$-based alloys under various conditions. For the as-heat-treated samples, the microhardness of grain interior in the alloys with low iron contents is slightly higher than that in alloys with high iron contents, while the change in phosphorus has no obvious effect on the micro-hardness. The effects of phosphorus and iron additions on the hardness of the alloys in the asheat-treated state are consistent with that on the tensile properties at $650{ }^{\circ} \mathrm{C}$. For the samples crept for $60 \mathrm{~h}$, the

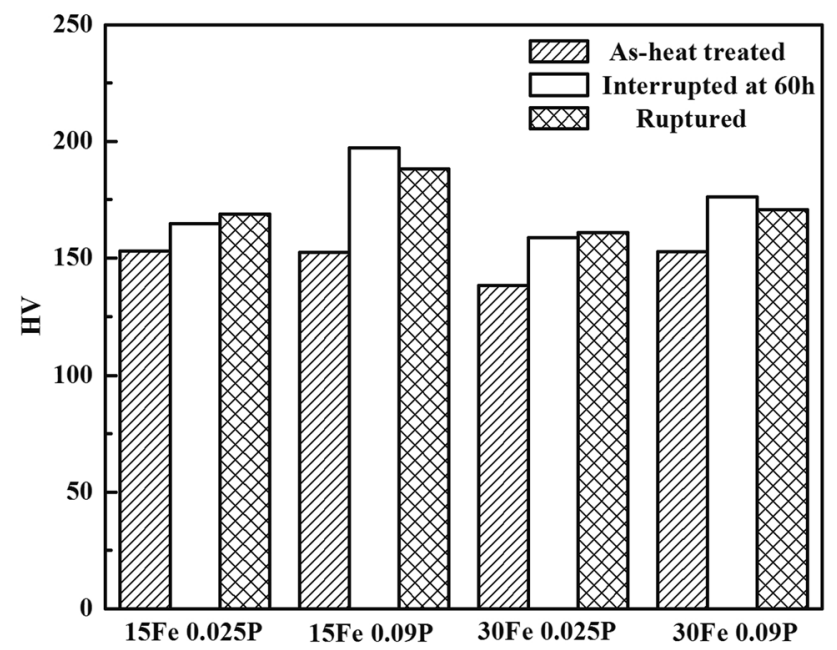

Fig. 3 Vickers hardness in the grain interior of alloys under different conditions hardness of all four alloys is enhanced compared to that of the as-heat-treated samples. Above all, the hardness of the alloy 2 is improved by a relatively large margin with the addition of phosphorus, and the strengthening role of phosphorus inner grains is highlighted. It is indicated that the increase in phosphorus enhances the strength of grain interior during creep test. For the samples after creep fracture, the micro-hardness has no obvious change in alloys with $0.025 \mathrm{wt} \%$ phosphorus but decreases in alloys with $0.09 \mathrm{wt} \%$ phosphorus. Therefore, the variation of hardness is concerned with the addition of phosphorus and iron.

\subsection{Microstructural Evolution During Creep Tests}

From the experimental results above, the mechanical properties were greatly affected by the interactions between phosphorus and iron, especially for the creep properties. In order to clarify the effects on creep properties, the microstructural evolution during creep tests was investigated. The fractographs of the $\mathrm{NiCrFe}$-based alloys are shown in Fig. 4. Phosphorus has a noticeable effect on the fracture mode of the $\mathrm{Ni}-17 \mathrm{wt} \% \mathrm{Cr}-15 \mathrm{wt} \% \mathrm{Fe}$ alloys. The fracture surface of the alloy 1 is flat with the typical transgranular fracture characteristics (Fig. 4a) and with a plenty of dimples located on the fracture surface (Fig. 4b). In alloy 2, most areas of the fracture surface present typical intergranular fracture characteristic (Fig. 4c) with the grain boundaries exposed clearly as shown in Fig. 4d. Comparatively, phosphorus has little effect on the fracture modes of $\mathrm{Ni}-17 \mathrm{wt} \% \mathrm{Cr}-30 \mathrm{wt} \% \mathrm{Fe}$ alloys. Both alloy 3 and alloy 4 present a transgranular fracture mode as shown in Fig. 4e, g, with dimples located on the fracture surfaces as shown in Fig. 4f, h. However, the dimples on the fracture surfaces of alloy 3 and alloy 4 are less and shallower than those on the fracture surface of alloy 1 .

Figures 5 and 6 show the micrographs of longitudinal section in the interrupted and fractured samples, respectively. In the samples crept at $60 \mathrm{~h}$, some scattered granular precipitations with an average size of $0.3-0.5 \mu \mathrm{m}$ were formed at grain boundaries in alloy 1 and alloy 3 (Fig. 5a, c). In addition to the granular precipitations, another irregularly shaped precipitations with the size of about $1 \mu \mathrm{m}$ indicated by the arrows also precipitated at grain boundaries in alloy 2 and alloy 4 (Fig. 5b, d). As shown in Fig. 6, the irregularly shaped precipitations in Fig. 6a, c are enriched with $\mathrm{P}$, and it was characterized as $M_{3} \mathrm{P}$ ( $M$ represents $\mathrm{Ni}, \mathrm{Cr}, \mathrm{Fe}$ ) phase with tetragonal crystal structure according to the selected area electron diffraction (SAED) patterns. As shown in Fig. 6b, d, the granular precipitations are enriched with $\mathrm{Cr}$ and $\mathrm{C}$ and are determined as $M_{23} \mathrm{C}_{6}$ carbides according to the SAED patterns [16]. It is indicated that the increase in phosphorus promotes the 

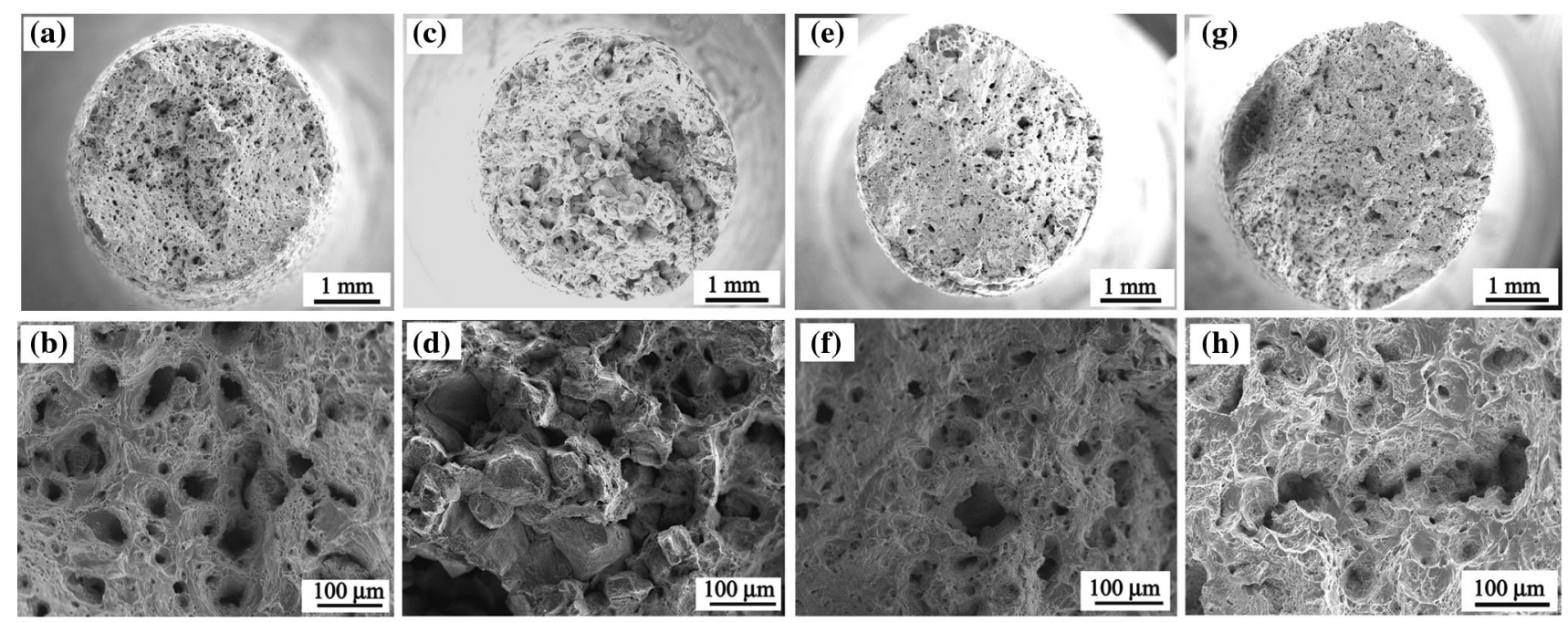

Fig. 4 Fractographs of the samples crept to rupture at $650{ }^{\circ} \mathrm{C}$ with an initial stress of $150 \mathrm{MPa}$ : a, b alloy $1 ; \mathbf{c}, \mathbf{d}$ alloy $2 ; \mathbf{e}, \mathbf{f}$ alloy $3 ; \mathbf{g}, \mathbf{h}$ alloy 4
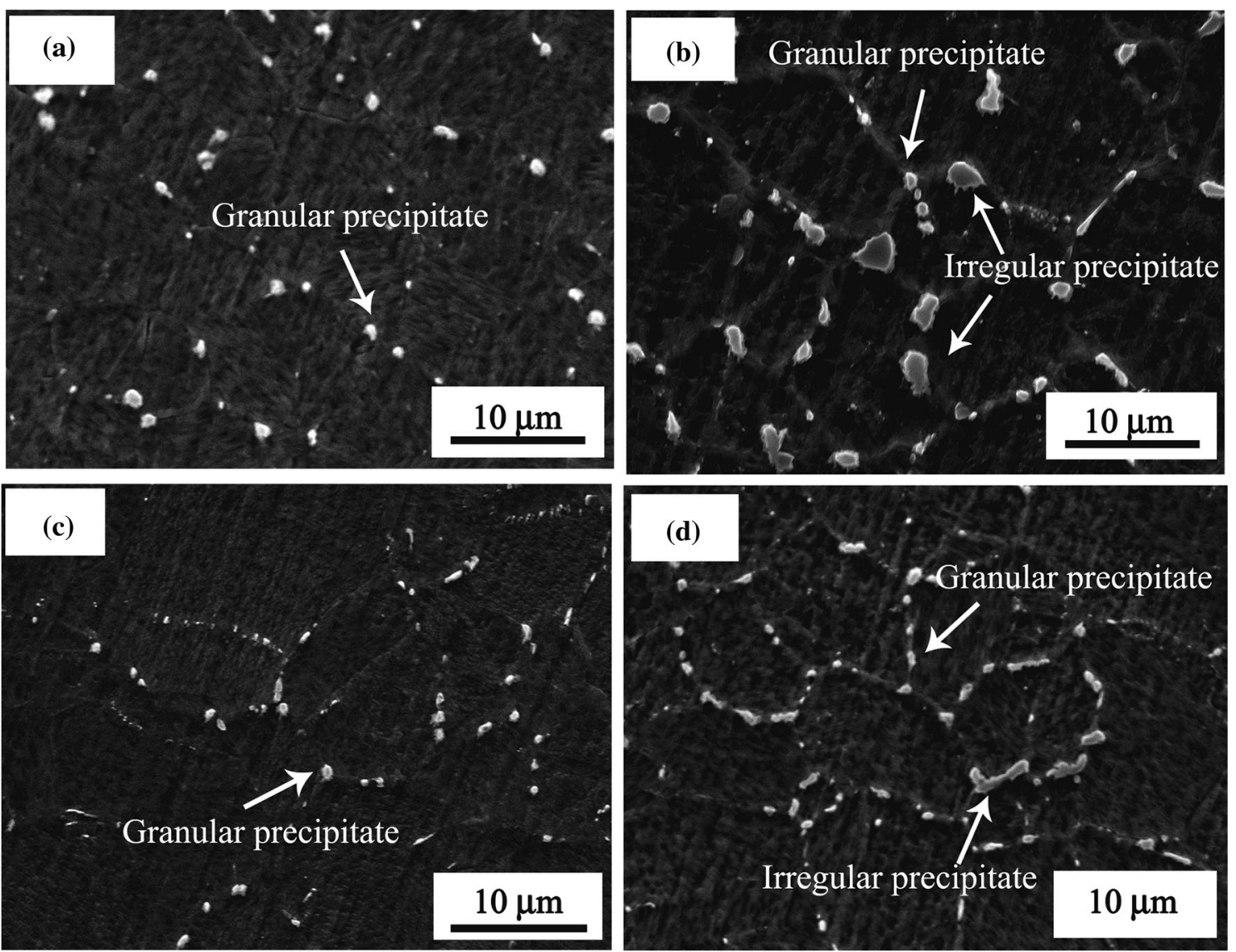

Fig. 5 Microstructure of alloys crept at $650{ }^{\circ} \mathrm{C}$ with an initial stress of $150 \mathrm{MPa}$ and interrupted at 60 h: a alloy 1 ; b alloy 2 ; c alloy 3 ; d alloy 4

precipitation of $M_{3} \mathrm{P}$. Although the additions of phosphorus in alloy 2 and alloy 4 are the same, the amount and size of $M_{3} \mathrm{P}$ are much larger in alloy 2 than those in alloy 4 , demonstrating that the increase in iron inhibits the formation of $M_{3} \mathrm{P}$.
Obviously, the size and the number of precipitations including $M_{23} \mathrm{C}_{6}$ and $M_{3} \mathrm{P}$ in these four alloys increase as the period of creep test becomes longer. Figure 7 shows the microstructures in the fractured samples. In alloy 1 and alloy 3, only $M_{23} \mathrm{C}_{6}$ precipitation is observed and its size 

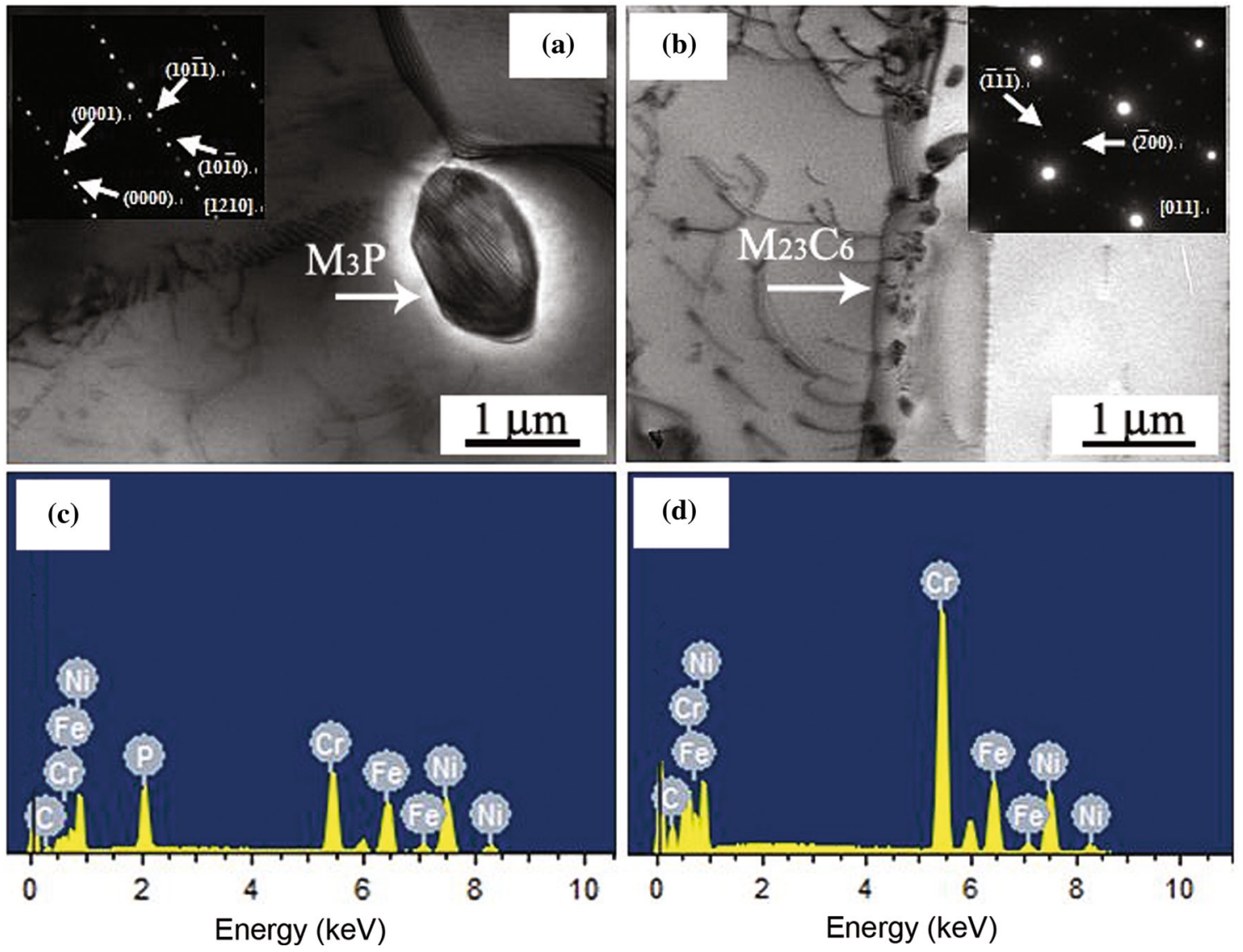

Fig. 6 TEM images, SAED patterns and EDS of the precipitates in alloy 2 crept for $60 \mathrm{~h}: \mathbf{a}, \mathbf{c} M_{3} \mathrm{P} ; \mathbf{b}, \mathbf{d} M_{23} \mathrm{C}_{6}$

becomes larger than that in the interrupted samples. In alloy 2 and alloy 4 , both $M_{23} \mathrm{C}_{6}$ and $M_{3} \mathrm{P}$ grow up and become twice or triple the size of that in alloys crept for $60 \mathrm{~h}$, especially in alloy 2 (Fig. 7b).

Due to the excellent creep performance of the alloy 2, many researches are focused on the interactions between dislocations and precipitates in the specimens after creep tests. In the steady stage of creep test (interrupted at $60 \mathrm{~h}$ ), $M_{23} \mathrm{C}_{6}$ precipitations along the grain boundaries with some dislocations piled up in the front of $M_{23} \mathrm{C}_{6}$. The grain boundaries are curved, demonstrating that the pin effect of $M_{23} \mathrm{C}_{6}$ keeps grain boundaries from sliding (Fig. 8a). When the $M_{3} \mathrm{P}$ precipitates along grain boundaries, wavy grain boundaries are formed because the curvature of grain boundaries is enlarged (Fig. $8 b$ ). Figure $8 c, d$ is the image obtained at the same place of the tested sample. Figure $8 \mathrm{c}$ focuses on the morphology of the $M_{3} \mathrm{P}$ precipitations at grain boundaries, while Fig. 8d lays emphasis on the dislocations pinned by curved grain boundaries. Curved grain boundaries demonstrate that the precipitation of $M_{3} \mathrm{P}$ can prevent grain boundaries from sliding effectively and dislocations are pinned by grain boundaries and stopped from moving.

\section{Discussion}

\subsection{Effects of Phosphorus and Iron on the Precipitations During Creep}

In the heat-treated alloys, no precipitations are formed at grain boundaries, as shown in Fig. 1. When the alloys are crept for $60 \mathrm{~h}$, some precipitations are found at grain boundaries. In alloy 1 and alloy $3, M_{23} \mathrm{C}_{6}$ precipitates uniformly at grain boundaries, while no phosphide is found. It is reported that the mechanical properties depend on the shape and distribution of precipitation at grain boundaries [17, 18]. Small and uniformly distributed $M_{23} \mathrm{C}_{6}$ at grain boundaries can improve the creep properties [19]. In alloy 2 and alloy $4, M_{3} \mathrm{P}$ and $M_{23} \mathrm{C}_{6}$ both precipitate at grain boundaries. The precipitation of phosphides is ascribed to the increasing phosphorus which exceed the degree of solid solubility for matrix. During creep tests, oversaturated phosphorus atoms and phosphating elements like $\mathrm{Cr}$ and $\mathrm{Ni}$ segregate to the grain boundaries accompanied with the movements of dislocations. The segregation of phosphorus atoms at grain boundaries will accelerate the formation and the growth of $M_{3} \mathrm{P}$. In addition, the key element for phosphating and carbonating is $\mathrm{Cr}$ 

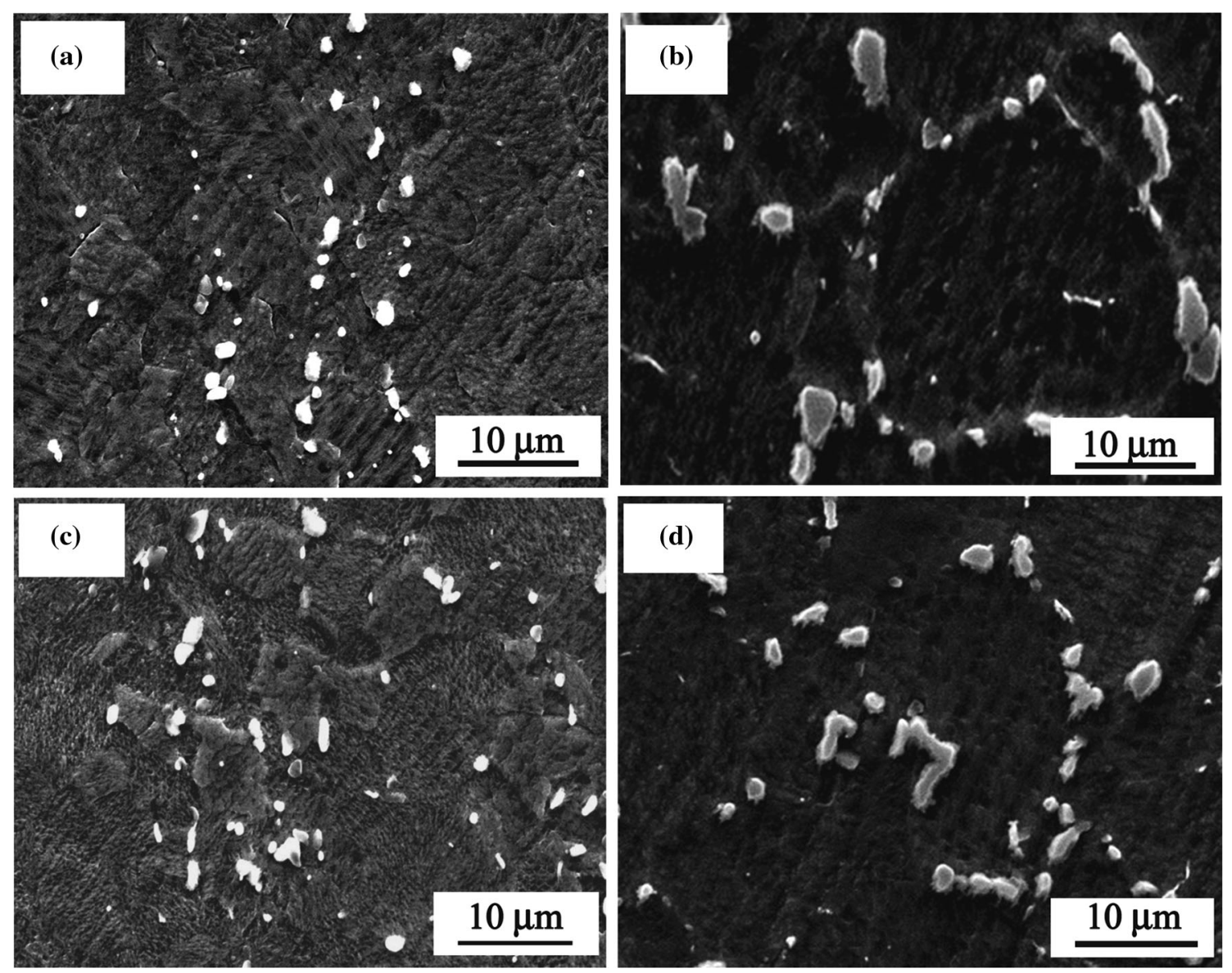

Fig. 7 Microstructures of the alloys crept to rupture at $650{ }^{\circ} \mathrm{C}$ with an initial stress of $150 \mathrm{MPa}$ : a alloy 1 ; b alloy 2 ; c alloy 3 ; d alloy 4

element $[20,21]$. Therefore, the formation of $M_{3} \mathrm{P}$ indirectly enhances the stability of $M_{23} \mathrm{C}_{6}$, which may improve the strength of grain boundaries further.

\subsection{Effects of Phosphorus and Iron on Mechanical Properties}

From the mechanical properties tested above, the addition of iron decreases the tensile strength and creep rupture life of the NiCrFe-based alloys. However, the addition of phosphorus improves the creep properties and the Vickers micro-hardness within the grain interior of the alloys under specific conditions. Firstly, the alloys with $0.025 \mathrm{wt} \%$ phosphorus (alloy 1 and alloy 3) are discussed. Transgranular fracture modes are dominated, which indicates that the strength of grain interior is lower than that of grain boundaries. The reason is probably attributed to the precipitation of $M_{23} \mathrm{C}_{6}$ at grain boundaries, which can enhance the strength of grain boundaries and prevent the movement of dislocations (Fig. 8a). The creep life of the alloy 1 is longer than that of alloy 3 , because the increment of the iron content in the matrix leads to the reduction in nickel content and brings in the decrease in matrix strength. The dislocations can slide more easily in the alloy with a lower yield strength, and it is much more difficult for phosphorus to prevent the moving of dislocations. The decrease in yield strength and micro-hardness both support this point.

For $\mathrm{Ni}-17 \mathrm{wt} \% \mathrm{Cr}-15 \mathrm{wt} \% \mathrm{Fe}$ alloys (alloy 1 and alloy 2 ), the creep life expectancy in the alloy 2 is more than twice as long as that in the alloy 1 . Furthermore, the fracture mode changes from transgranular fracture to intergranular fracture with the increase in phosphorus from 0.025 to $0.09 \mathrm{wt} \%$. It is demonstrated that the strength of grain interior is higher than that of grain boundaries in the alloy 2. It can be deduced that the addition of phosphorus improves the strength of both interior grains and grain boundaries. The precipitation of $M_{3} \mathrm{P}$ at grain boundaries demonstrates that phosphorus atoms have exceeded the solubility of matrix for phosphorus. No precipitation in grains indicates that phosphorus atoms have solubilized in the matrix. It should be noted that the solid solution hardening effect of phosphorus may exist [22, 23]. The increase in hardness at the steady stage of creep shows that the phosphorus atoms can increase the strength of grain interior by improving solid solution strengthening effect after sufficiently diffused into matrix. The improvement in 

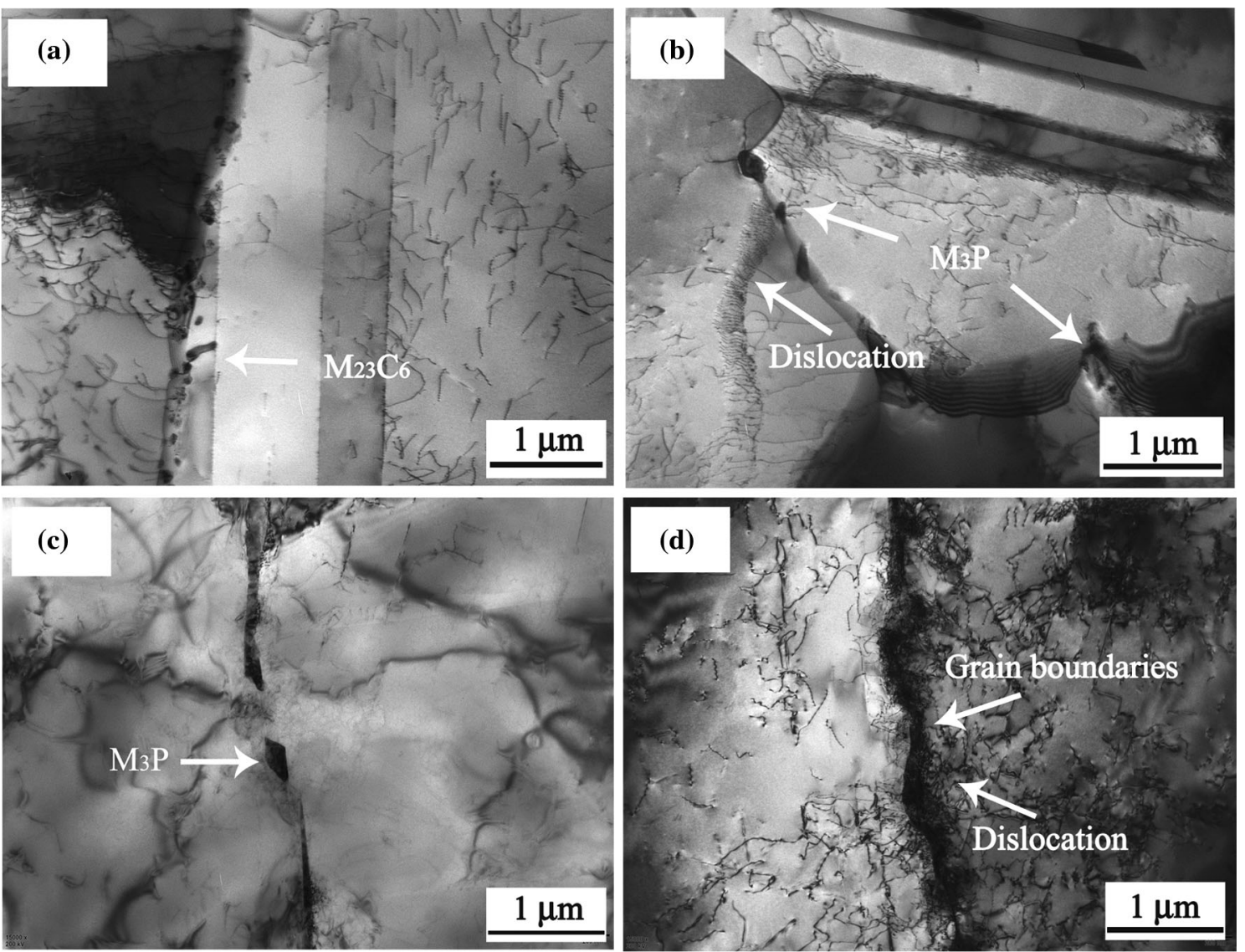

Fig. 8 Dislocation patterns in alloy 2 crept for $60 \mathrm{~h}$ around a $M_{23} \mathrm{C}_{6}$ and $\mathbf{b} M_{3} \mathrm{P}$; TEM images at the same place of $M_{3} \mathrm{P}$ c; grain boundaries d

internal grain strength caused by phosphorus is the main reason for the enhancement of creep performance. It is because that the phosphorus atoms can stop the dislocations from sliding and thus inhibit the deformation of matrix. However, the decrease in hardness at the tertiary creep stage is attributed to the nucleation and growth of intergranular $M_{3} \mathrm{P}$, which consumes phosphorus atoms in matrix and thus reduces the effect of solution strengthening. Furthermore, the precipitation of $M_{3} \mathrm{P}$ with small size at grain boundaries in the primary stage of creep tests hinders the motion of dislocations and thus inhibits the deformation of the matrix (Fig. 8c, d). At the tertiary creep stage, $M_{3} \mathrm{P}$ grows up which brings in the disappearance of precipitation strengthening effect and promotes the formation of microcracks. Therefore, the oversize of $M_{3} \mathrm{P}$ precipitated at grain boundaries becomes the main cause for creep rate acceleration and thus resulting in intergranular fracture.

For the Ni-17 wt $\% \mathrm{Cr}-30 \mathrm{wt} \% \mathrm{Fe}$ alloys (alloy 3 and alloy 4), the improvement in creep life by phosphorus additions is also attributed to the solid solution strengthening, although the rise is not higher. It is because the solid solubility in high iron-doped alloys for phosphorus is increased, and solution strength effect is relatively weaker than that in alloy 2 [24]. Thus, the increase in interior grains strength caused by phosphorus is not as obvious as the alloy 2. Insufficient strength of interior grains results in the final transgranular fracture of creep samples. Therefore, the solid solubility of matrix for phosphorus influences the effect of solution strengthening directly. It implies that phosphorus atoms can both dissolve in the matrix and concentrate at grain boundaries noticeably. So, the solid solution strengthening effect of phosphorus and optimization of grain boundary precipitates by phosphorus are the main factors for the increase in creep life.

\section{Conclusion}

Various phosphorus and iron contents have significant effects on the creep properties. The results show that the alloy with $15.8 \mathrm{wt} \%$ iron and $0.09 \mathrm{wt} \%$ phosphorus possesses the longest creep life. The addition of iron reduces the yield strength and creep rupture life of the $\mathrm{NiCrFe}$ based alloys. However, the addition of phosphorus plays an important role in enhancing the strength of both interior grains and grain boundaries. The solid solution strengthening effect of phosphorus atoms dissolved in matrix is the 
main cause for improving interior strength and thus prolongs the creep life. Small-sized $M_{23} \mathrm{C}_{6}$ and $M_{3} \mathrm{P}$ promoted by oversaturated phosphorus atoms can also strengthen the grain boundaries and hinder the motions of dislocations.

\section{References}

[1] C. Wang, H. Zhao, Y. Guo, J. Guo, L. Zhou, Mater. Res. Innov. 18, 325 (2014)

[2] L. Zheng, T.D. Xu, Q. Deng, J.X. Dong, Mater. Lett. 62, 55 (2008)

[3] W.R. Sun, S.R. Guo, J.T. Guo, D.Z. Lu, Z.Q. Hu, Acta Metall. Sin. (Engl. Lett.) 31, 349 (1995)

[4] W.R. Sun, S.R. Guo, D.Z. Lu, Z.Q. Hu, Met. Mater. Trans. A 28, 649 (1997)

[5] S.L. Yang, W.R. Sun, J.X. Wang, Z.M. Ge, S.R. Guo, Z.Q. Hu, J. Mater. Sci. Technol. 27, 539 (2011)

[6] Z.Q. Hu, W.R. Sun, S.R. Guo, Acta Metall. Sin. (Engl. Lett.) 9, 443 (1996)

[7] S. Zhang, X. Xin, L.X. Yu, A.W. Zhang, W.R. Sun, X.F. Sun, Metall. Mater. Trans. A 47, 1 (2016)

[8] S.R. Guo, W.R. Sun, D.Z. Lu, Z.Q. Hu, in Superalloys 718, 625, 706 and Various Derivativesed, ed. by E.A. Loria (TMS, Warrendale, 1997), p. 521

[9] X.B. Liu, J.X. Dong, B. Tang, Y. Hu, X.S. Xie, Mater. Sci. Eng., A 270, 190 (1999)
[10] C.G. McKamey, C.A. Carmichael, W.D. Cao, R.L. Kennedy, Scr. Mater. 38, 485 (1998)

[11] X. Liu, H. Liu, J. Dong, X. Xie, Scr. Mater. 42, 189 (2006)

[12] Z.Q. Hu, W.R. Sun, S.R. Guo, D.Z. Lu, Chin. J. Nonferrous Met. 11, 947 (2001)

[13] M.Q. Wang, J.H. Du, Q. Deng, Z.L. Tian, J. Zhu, Mater. Sci. Eng., A 626, 382 (2015)

[14] L.X. Yu, Y.R. Sun, W.R. Sun, X.F. Sun, S.R. Guo, Z.Q. Hu, Mater. Sci. Eng., A 527, 911 (1998)

[15] W.D. Cao, R.L. Kennedy, in Superalloys, ed. by R.D. Kissinger (TMS, Warrendale, 1996), p. 597

[16] H.U. Hong, B.S. Rho, S.W. Nam, Mater. Sci. Eng., A 318, 292 (2001)

[17] R.M. Wang, Y.G. Song, Y.F. Han, J. Alloys Compd. 311, 402 (2000)

[18] Q.Z. Chen, C.N. Jones, D.M. Knowles, Mater. Sci. Eng., A 385, 418 (2004)

[19] S. Guan, C.Y. Cui, Y. Y, Y.F. Gu. Mater. Sci. Eng., A 662, 279 (2016)

[20] T. Lin, Y. Guo, Z. Wang, H.P. Shao, H.Y. Lu, F.H. Li, X.B. He, Int. J. Refract. Met. Hard Mater. 72, 228 (2018)

[21] W.M. Gui, H.Y. Zhang, M. Yang, T. Jin, X.F. Sun, Q. Zheng, J. Alloys Compd. 695, 1272 (2017)

[22] W.M. Guo, Z.C. Wang, Y.D. Li, N. Xu, J.B. Shi, Metallogr. Microstruct. Anal. 2, 255 (2013)

[23] X.L. Song, Z.X. Yuan, J. Jia, D. Wang, L.X. Fan, Scr. Mater. 63, $448(2010)$

[24] H. Okamoto, Bull. Alloys Phase Diagr. 11, 405 (1990) 